\title{
Fasting plasma mannose levels are associated with insulin sensitivity independent of BMI in Japanese individuals with diabetes
}

\author{
Eri Amano, Shogo Funakoshi, Kumiko Yoshimura, Seiki Hirano, Satoko Ohmi, Hiroshi Takata, Yoshio Terada \\ and Shimpei Fujimoto*
}

\begin{abstract}
Background: Recently, an integrated network analysis has revealed dysregulation in the metabolism of mannose, a glucose epimer, in severely obese individuals without diabetes. In addition, fasting plasma mannose levels $\left(M_{0}\right)$ are associated with insulin resistance independent of BMI. Since the association between mannose and insulin sensitivity (IS) in those with impaired glucose tolerance remains unknown, we aimed to investigate this association in individuals without severe obesity but with varying degrees of glucose tolerance.
\end{abstract}

Methods: Based on $75 \mathrm{~g}$ OGTT data in Japanese individuals without diabetic medication, individuals were classified as having normal glucose tolerance (NGT), impaired glucose metabolism (IGM), or diabetes (DM). In each group, 25 individuals were consecutively recruited [total 75 individuals, age: $65 \pm 11$ (mean \pm SD); BMl: $24.9 \pm 3.8 \mathrm{~kg} /$ $\mathrm{m}^{2}$ ]. QUICKI and Matsuda index (MI) were calculated as IS indices. $\mathrm{M}_{0}$ was assayed using HPLC. Normally-distributed $\log _{e}$-transformed (In-) values were used for Ml and leptin.

Results: In the simple regression analysis, In-MI was negatively correlated with BMI (NGT: $r=-0.639$, IGM: $r=-0.466, D M: r=-0.613$ ) and In-leptin (NGT: $r=-0.480, \mathrm{IGT}: r=-0.447, \mathrm{DM}: r=-0.593)$ in all 3 groups. Ln-MI was not significantly correlated with $M_{0}$ in NGT $(r=0.241, P=0.245)$ and IGT $(r=-0.296, P=0.152)$ groups, it was moderately and negatively correlated in the DM group $(r=-0.626, P<0.001)$. Similar results were obtained, when QUICKI was used instead of $\mathrm{MI}$ as an index of IS. In multiple regression analysis in the DM group, QUICKI (Q) and In-MI $(M)$ were independently predicted by $B M I(Q: \beta=-0.413 ; M: \beta=-0.400)$ and $M_{0}(Q: \beta=-0.413, M: \beta=-0.426)$, accounting for $51.2 \%(P=0.0004)$ and $51.2 \%(P=0.0004)$ of the variability, respectively, which was larger than the prediction for BMI alone (Q: 38.4\%, M: 37.6\%).

Conclusion: Fasting plasma mannose was associated with IS independent of BMI in Japanese individuals with DM.

Keywords: Insulin resistance, BMl, Mannose, Glucose intolerance

\section{Background}

Obesity is an important factor in the pathogenesis of insulin resistance and substantially increases the risk of type 2 diabetes [1]. To identify novel metabolic biomarkers of obesity, profiling of omics data on obese and lean individuals and a comparison between them

\footnotetext{
*Correspondence: fujimoto@kochi-u.ac.jp
}

Department of Endocrinology, Metabolism, and Nephrology, Kochi Medical School, Kochi University, Kohasu, Oko-cho, Nankoku, Kochi 783-8505, Japan has been performed [2-4]. Recently, cell-specific integrated network analysis has revealed dysregulation in the metabolism of mannose in individuals with severe obesity who do not have significant diabetes [4]. Mannose, an epimer of glucose, is a monosaccharide constituent of glycoproteins and glycolipids. In humans, the mean concentrations of plasma mannose are approximately between 40 and $50 \mu \mathrm{M}$ [5-7]. Interestingly, fasting plasma mannose levels $\left(\mathrm{M}_{0}\right)$ are higher in the obese subjects compared to those in the lean subjects and are associated with insulin resistance independent of BMI. 
Moreover, downregulation of mannose phosphorylation occurs in the liver of obese individuals, which may lead to decreased plasma mannose utilization and increase in $\mathrm{M}_{0}$ [4]. However, the association between mannose and insulin sensitivity in those with diabetes remains unknown, although insulin resistance plays an important role in the pathogenesis of type 2 diabetes [1] and dysregulation of plasma mannose levels has been reported in type 2 diabetes $[6,7]$. This study aimed to investigate the association between mannose and insulin sensitivity in individuals with varying degrees of glucose tolerance.

\section{Methods}

\section{Participants}

We analyzed data derived from 75 -g oral glucose tolerance test (OGTT) involving 75 Japanese individuals without diabetic medication as described previously [sex (M/F): 34/41; age: $65 \pm 11$ (mean $\pm \mathrm{SD})$; BMI: $\left.24.9 \pm 3.8 \mathrm{~kg} / \mathrm{m}^{2}\right]$ [7].

\section{Laboratory examinations and anthropometric data}

Based on 75 g OGTT data, individuals were either classified as normal glucose tolerance (NGT), impaired glucose metabolism (IGM), or diabetes (DM) according to 2006 WHO criteria [8] [NGT, fasting plasma glucose $(\mathrm{FPG})<6.1 \mathrm{mmol} / \mathrm{L}$ and 2 -h plasma glucose $(2-\mathrm{h}$ PG) $<7.8 \mathrm{mmol} / \mathrm{L}$; IGM, either impaired fasting glucose (IFG, FPG $\geq 6.1$ and $<7.0 \mathrm{mmol} / \mathrm{L}$ ) and/or impaired glucose tolerance (IGT, 2-h PG $\geq 7.8$ and $<11.1 \mathrm{mmol} / \mathrm{L}$ ); $\mathrm{DM}, \mathrm{FPG} \geq 7.0 \mathrm{mmol} / \mathrm{L}$ and/or $2-\mathrm{h} \mathrm{PG} \geq 11.1 \mathrm{mmol} / \mathrm{L}]$. In each group, 25 participants were consecutively recruited. Plasma glucose, immunoreactive insulin (IRI), and mannose were measured using the glucose oxidase method, ELISA, and HPLC, as previously described [7]. Serum leptin, a biomarker for body fat mass [9], was measured using ELISA (Quantikine ${ }^{\circledR}$ ELISA, R\&D Systems, Minneapolis, MN, USA). Although fasting plasma glucose $\left(\mathrm{G}_{0}\right)$, plasma glucose and mannose $120 \mathrm{~min}$ after glucose load $\left(\mathrm{G}_{120}\right.$ and $\mathrm{M}_{120}$, respectively), fasting plasma mannose $\left(\mathrm{M}_{0}\right)-\mathrm{M}_{120}$, and HbA1c were significantly different among the 3 groups, age, sex, BMI, and $\mathrm{M}_{0}$ were not significantly different [7].

\section{Indices of insulin secretion and insulin sensitivity}

Indices of insulin secretion and insulin sensitivity were calculated using glucose and IRI data from the $75-\mathrm{g}$ OGTT, as previously described [7, 10]. QUICKI and Matsuda index (MI) were calculated as indices of insulin sensitivity. The insulinogenic index (IGI) and HOMA- $\beta$ were calculated as indices of insulin secretion. The oral disposition index $\left(\mathrm{DI}_{\mathrm{O}}\right)$ was calculated as an index of insulin secretion adjusted for insulin sensitivity. IGI,
QUICKI, MI and $\mathrm{DI}_{\mathrm{O}}$ were significantly different among the NGT, IGM, and DM groups, but HOMA- $\beta$ was not significantly different [7].

\section{Statistical analysis}

Non-normally distributed continuous data are presented as median values, and 25th and 75th percentile values. The Kruskal-Wallis test was used to determine differences for non-normally distributed continuous data among more than three groups. The relationship between the parametric data was determined using Pearson analysis. In regression analyses, Normally-distributed $\log _{\mathrm{e}}$-transformed (ln-) values were used for MI, leptin, and high-density lipoprotein-cholesterol (HDL-C). P values $<0.05$ were considered statistically significant.

\section{Results}

\section{Simple regression analyses}

Serum leptin and HDL-C were not significantly different among the 3 groups (Table 1). QUICKI was negatively correlated with BMI (NGT: $r=-0.654$, IGM: $\mathrm{r}=-0.538, \mathrm{DM}: \mathrm{r}=-0.620$ ) and ln-leptin (NGT: $r=-0.581$, IGM: $r=-0.486$, DM: $r=-0.606)$ in all 3 groups. Ln-MI was negatively correlated with BMI (NGT: $r=-0.639$, IGM: $r=-0.466, D M: r=-0.613$ ) and ln-leptin (NGT: $\mathrm{r}=-0.480$, IGM: $\mathrm{r}=-0.447$, DM: $r=-0.593$ ) in all 3 groups (Table 2, Figs. 1, 2). Interestingly, although QUICKI and ln-MI were not significantly correlated with $\mathrm{M}_{0}$ in the NGT group (QUICKI: $\mathrm{r}=0.297, P=0.1499$; ln-MI: $\mathrm{r}=0.241, P=0.2453)$ and in the IGM group (QUICKI: $\mathrm{r}=-0.365, P=0.0732$; ln-MI: $\mathrm{r}=-0.296, P=0.1515)$, they were moderately and negatively correlated in the DM group (QUICKI: $\mathrm{r}=-0.620, P=0.0010$; ln-MI: $\mathrm{r}=-0.626, P=0.0008$ ) (Table 3, Figs. 1, 2). In contrast, a decrease in mannose levels after a glucose load $\left(\mathrm{M}_{120}-\mathrm{M}_{0}\right)$ was associated with QUICKI in the NGT group $(\mathrm{r}=-0.462$, $\mathrm{P}=0.0210$ ) but not in the IGM and DM groups (IGM: $\mathrm{r}=0.295, \quad P=0.1571 ; \quad \mathrm{DM}: \quad \mathrm{r}=0.066, \quad P=0.7538)$ (Table 3).

Table 1 Serum leptin and HDL-C levels in the NGT, IGM and DM groups

\begin{tabular}{|c|c|c|c|c|}
\hline & NGT & IGM & DM & $P$ value \\
\hline $\mathrm{n}$ & 25 & 25 & 25 & \\
\hline $\begin{array}{l}\text { Leptin (ng/ } \\
\text { mL) }\end{array}$ & $\begin{array}{l}6.08 \\
(2.28,12.35)\end{array}$ & $\begin{array}{l}7.17 \\
\quad(2.92,16.88)\end{array}$ & $\begin{array}{l}6.57 \\
\quad(4.53,12.79)\end{array}$ & 0.5011 \\
\hline $\begin{array}{l}\mathrm{HDL}-\mathrm{C}(\mathrm{mg} / \\
\mathrm{dL})\end{array}$ & $\begin{array}{l}59.6 \\
\quad(50.2,65.1)\end{array}$ & $\begin{array}{l}50.2 \\
\quad(43.8,62.0)\end{array}$ & $\begin{array}{l}55.2 \\
\quad(48.0,64.5)\end{array}$ & 0.0841 \\
\hline
\end{tabular}

Median values are shown. The 25 th percentile and 75 th percentile values are shown in parenthesis 
Table 2 Simple correlation between insulin sensitivity indices and clinical factors in the NGT, IGM, and DM groups

\begin{tabular}{|c|c|c|c|c|c|c|}
\hline & \multicolumn{6}{|l|}{ QUICKI } \\
\hline & \multicolumn{2}{|l|}{ NGT } & \multicolumn{2}{|l|}{ IGM } & \multicolumn{2}{|l|}{ DM } \\
\hline & $r$ & $P$ & $r$ & $P$ & $r$ & $P$ \\
\hline Age & 0.146 & 0.4827 & 0.611 & 0.0012 & 0.600 & 0.0015 \\
\hline Sex & 0.197 & 0.3443 & -0.117 & 0.5789 & -0.255 & 0.2189 \\
\hline BMI & -0.654 & 0.0004 & -0.538 & 0.0055 & -0.620 & 0.0010 \\
\hline WC & -0.600 & 0.0015 & -0.399 & 0.0483 & -0.470 & 0.0178 \\
\hline $\mathrm{HbA1c}$ & -0.342 & 0.0943 & 0.179 & 0.3931 & -0.354 & 0.0827 \\
\hline $\log _{e}-$ leptin & -0.581 & 0.0023 & -0.486 & 0.0137 & -0.606 & 0.0013 \\
\hline \multirow[t]{4}{*}{$\log _{e}-H D L-C$} & 0.272 & 0.1879 & -0.022 & 0.9176 & 0.273 & 0.1875 \\
\hline & \multicolumn{6}{|l|}{$\log _{\mathrm{e}}-\mathrm{MI}$} \\
\hline & \multicolumn{2}{|l|}{ NGT } & \multicolumn{2}{|l|}{ IGM } & \multicolumn{2}{|l|}{ DM } \\
\hline & $r$ & $P$ & $r$ & $P$ & $r$ & $P$ \\
\hline Age & 0.103 & 0.6257 & 0.614 & 0.0011 & 0.527 & 0.0068 \\
\hline Sex & 0.046 & 0.8257 & -0.116 & 0.5815 & -0.260 & 0.2096 \\
\hline BMI & -0.639 & 0.0006 & -0.466 & 0.0188 & -0.613 & 0.0011 \\
\hline WC & -0.573 & 0.0027 & -0.419 & 0.0369 & -0.535 & 0.0059 \\
\hline $\mathrm{HbA1c}$ & -0.289 & 0.1610 & 0.165 & 0.4312 & -0.215 & 0.3026 \\
\hline $\log _{e}$-leptin & -0.480 & 0.0151 & -0.447 & 0.0250 & -0.593 & 0.0018 \\
\hline $\log _{e}-H D L-C$ & 0.128 & 0.5415 & -0.054 & 0.7962 & 0.231 & 0.2657 \\
\hline
\end{tabular}

$G_{0}$ fasting plasma glucose, $W C$ waist circumference, $M I$ Matsuda Index

\section{Multiple regression analyses in the DM group}

QUICKI was independently predicted by BMI $(\beta=-0.413)$ and $\mathrm{M}_{0}(\beta=-0.413)$, accounting for $51.2 \%(P=0.0004)$ of the variability (Model 1$)$, and by ln-leptin $(\beta=-0.414)$ and $\mathrm{M}_{0}(\beta=-0.438)$ accounting for $52.2 \%(P=0.0003)$ of the variability (Model 2$)$ (Table 4), which was larger than that for predictions by BMI alone (38.4\%) and ln-leptin alone (36.7\%). Ln-MI was independently predicted by BMI $(\beta=-0.400)$ and $\mathrm{M}_{0}(\beta=-0.426)$, accounting for $51.2 \%(P=0.0004)$ of the variability (Model 3$)$, and by ln-leptin $(\beta=-0.394)$ and $\mathrm{M}_{0}(\beta=-0.453)$ accounting for $51.7 \%(P=0.0003)$ of the variability (Model 4) (Table 4), which was larger for predictions by BMI alone (37.6\%) and ln-leptin alone (35.1\%).

\section{Discussion}

Insulin resistance is established as a precursor of type 2 diabetes and cardiovascular disease [1]. Since insulin resistance is commonly found in obesity and weight reduction improves insulin resistance, adiposity plays an important role in the pathogenesis of insulin resistance. Although the mechanism by which obesity causes insulin resistance has not been fully elucidated, systemic inflammation, adipose-derived proinflammatory molecules, and free fatty acids may play important roles in the increase in insulin resistance [1]. However, obesity alone cannot explain insulin resistance completely. On the basis of this background, exploratory studies to find novel biomarkers related to insulin resistance independent of adiposity have been performed that have compared the metabolic profile between obese individuals without significant diabetes and lean individuals using metabolomics. These studies have revealed that branched-chain amino acids including leucine, isoleucine, and valine [2] and $\alpha$-hydroxybutyrate [3] are associated with insulin sensitivity independent of adiposity. Recently, a cell-specific integrated network analysis that merged genome-scale metabolic, transcriptional regulatory, and protein-protein interaction networks revealed dysregulation in the metabolism of mannose in individuals with severe obesity who did not have significant diabetes [4]. These results showed that the expression level of hexokinase, which mediates a limited step reaction in mannose utilization in the liver, was reduced in obese individuals. In addition, insulin sensitivity was associated with the fasting plasma mannose level independent of BMI. In the present study, an association between fasting plasma mannose levels and insulin sensitivity independent of BMI was observed in individuals with diabetes and not in individuals without diabetes. These results suggest the contribution of factors other than adiposity towards 


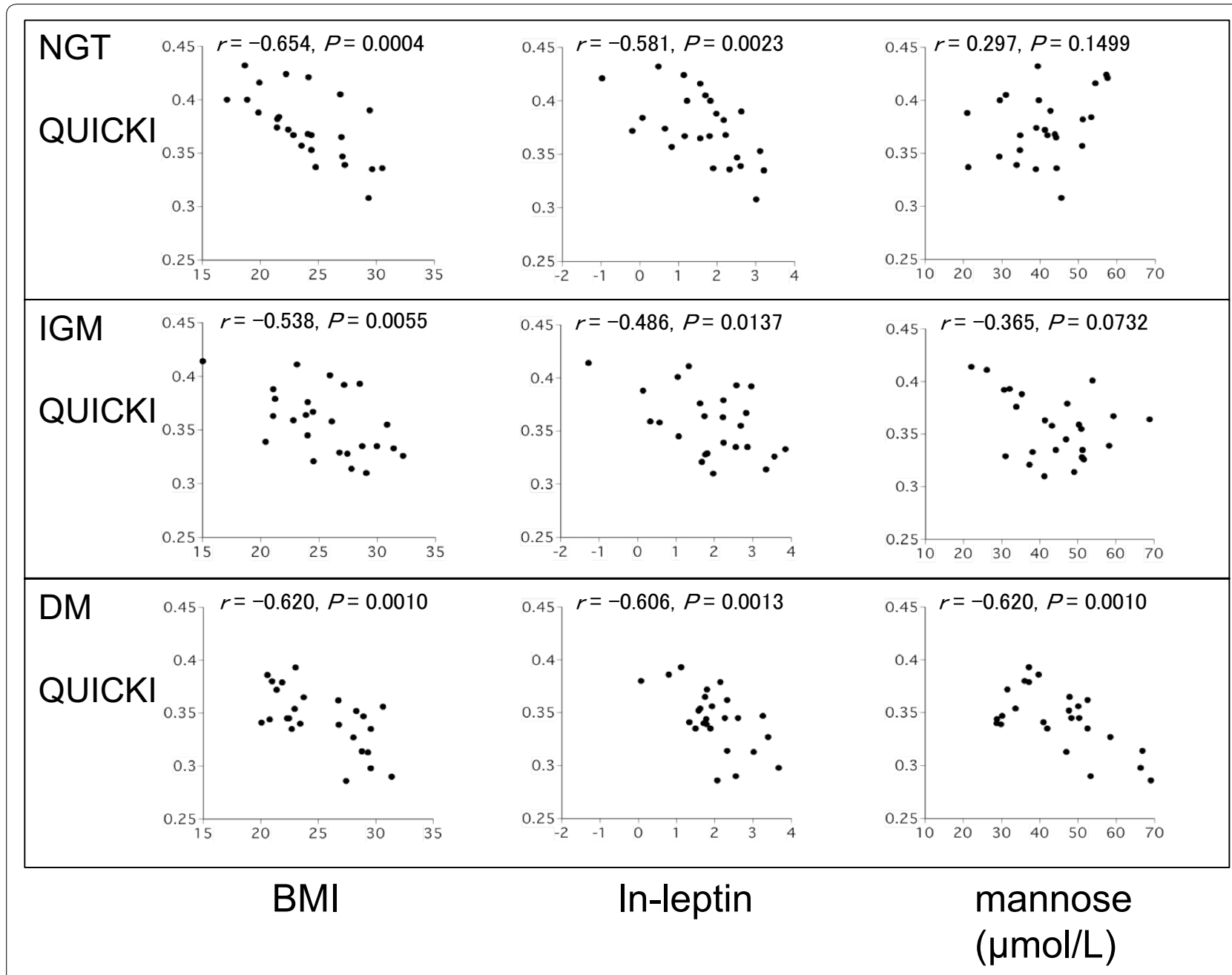

Fig. 1 Relationships between QUICKI and clinical factors including BMI, In-leptin, and fasting plasma mannose in NGT, IGM and DM groups $(n=25$ in each group)

insulin resistance in diabetes. Prediction of insulin sensitivity by BMI and fasting plasma mannose levels was more accurate than the prediction by BMI alone, which may contribute to more precise estimation of insulin sensitivity in patients with diabetes.

Since it has recently been reported that plasma mannose levels are significantly associated with a future risk of type 2 diabetes in cohort studies [11, 12], mannose metabolism might be dysregulated in the early phase of glucose intolerance. Fasting plasma mannose levels of individuals with diabetes (DM) are higher than those of individuals with NGT [6] and there is a close positive correlation between plasma glucose and mannose levels [13-15]. Experiments in rats have previously shown that the plasma mannose level decreases after glucose loading, but does not decrease in diabetic rats, and that hepatic glycogenolysis is a source of this plasma mannose [16]. We have clarified the relation between plasma mannose level and glucose tolerance in humans [7]. After glucose loading, the plasma mannose level decreased gradually in the NGT group, but did not decrease in the DM group. The plasma mannose changes, throughout $120 \mathrm{~min}$ following oral glucose loading from base line $\left(\mathrm{M}_{120}-\mathrm{M}_{0}\right)$, were significantly different among the NGT, IGM, and DM groups and were correlated with indices of insulin secretion and sensitivity. These results suggest that insufficient suppression of glycogenolysis due to impaired insulin secretion after glucose loading and hepatic insulin 


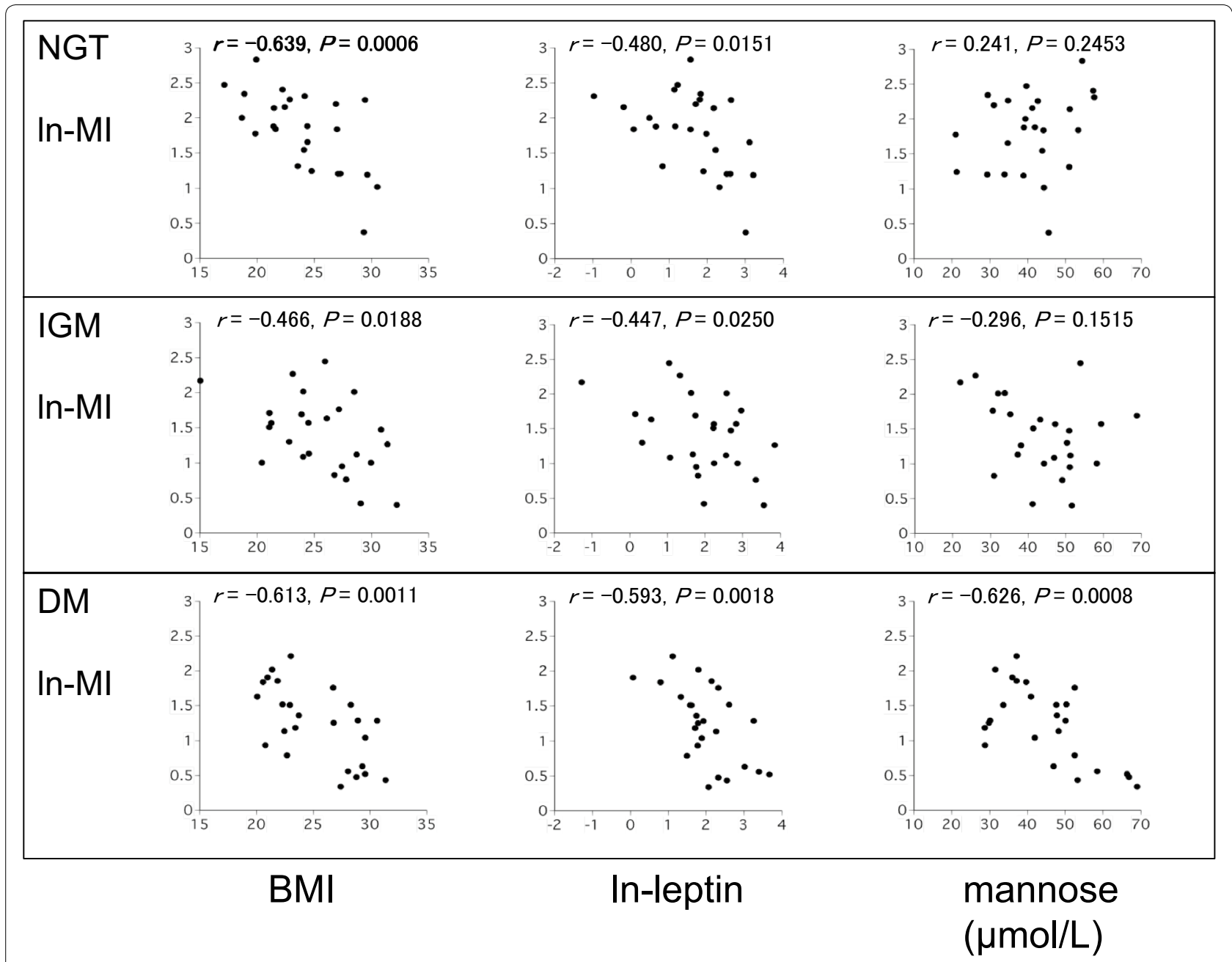

Fig. 2 Relationships between In-MI and clinical factors including BMI, In-leptin, and fasting plasma mannose in NGT, IGM and DM groups $(n=25$ in each group)

resistance in those with diabetes is linked to an enhanced mannose efflux from the liver and a blunted decrease in mannose levels after glucose loading in those with diabetes. The alteration of mannose utilization in the liver in diabetes remains unknown, and whether reduced mannose phosphorylation and utilization in the liver also occur in non-obese individuals with diabetes should be elucidated. Our results showing that $\mathrm{M}_{0}$ was correlated with QUICKI in the DM group only and that $\mathrm{M}_{120}-\mathrm{M}_{0}$ was correlated with QUICKI in the NGT group only suggest the influence of different ranges of insulin sensitivity on fasting and post-glucose-load mannose metabolism.

\section{Limitations}

The present study has several limitations. First, insulin sensitivity was not measured using a hyperinsulinemiceuglycemic clamp, which is the gold standard method. Second, since this study was cross-sectional, a causal 
Table 3 Simple correlation between insulin sensitivity/secretion indices and plasma mannose levels in the NGT, IGM, and DM groups

\begin{tabular}{|c|c|c|c|c|c|c|}
\hline & \multicolumn{6}{|l|}{$\mathrm{M}_{0}$} \\
\hline & \multicolumn{2}{|l|}{ NGT } & \multicolumn{2}{|l|}{ IGM } & \multicolumn{2}{|l|}{ DM } \\
\hline & $r$ & $P$ & $r$ & $P$ & $r$ & $P$ \\
\hline $\log _{e}-|G|$ & -0.177 & 0.5768 & -0.056 & 0.7913 & 0.381 & 0.0599 \\
\hline $\log _{e}-\mathrm{HOMA \beta}$ & -0.149 & 0.4781 & 0.023 & 0.9115 & 0.252 & 0.2234 \\
\hline $\log _{e}-D I_{0}$ & 0.068 & 0.7458 & -0.225 & 0.2795 & -0.057 & 0.7852 \\
\hline QUICKI & 0.297 & 0.1499 & -0.365 & 0.0732 & -0.620 & 0.0010 \\
\hline \multirow[t]{4}{*}{$\underline{\log }_{e}-M I$} & 0.241 & 0.2453 & -0.296 & 0.1515 & -0.626 & 0.0008 \\
\hline & \multicolumn{6}{|c|}{$M_{120}-M_{0}$} \\
\hline & \multicolumn{2}{|l|}{ NGT } & \multicolumn{2}{|l|}{ IGM } & \multicolumn{2}{|l|}{ DM } \\
\hline & $r$ & $P$ & $r$ & $P$ & $r$ & $P$ \\
\hline $\log _{e}-|G|$ & 0.303 & 0.1407 & -0.249 & 0.2305 & -0.323 & 0.1150 \\
\hline $\log _{e}-\mathrm{HOMA \beta}$ & 0.330 & 0.1067 & -0.141 & 0.5026 & -0.177 & 0.3917 \\
\hline $\log _{e}-D I_{0}$ & 0.007 & 0.9741 & -0.078 & 0.7105 & -0.325 & 0.1130 \\
\hline QUICKI & -0.462 & 0.0201 & 0.295 & 0.1571 & 0.066 & 0.7538 \\
\hline $\log _{e}-M l$ & -0.384 & 0.0578 & 0.273 & 0.1868 & 0.202 & 0.3325 \\
\hline
\end{tabular}

$M_{0}$ and $M_{120}$ are plasma mannose levels at 0 (fasting) and 120 min after glucose loading. $M_{120}-M_{0}$ is alteration of mannose levels during glucose loading ( $M_{120}$ minus $\mathrm{M}_{0}$ )

$I G I$ insulinogenic index, $D I_{O}$ oral disposition index, MI Matsuda index

Table 4 Multiple regression analyses for the determinants of insulin sensitivity in the DM group

\begin{tabular}{llll}
\hline Dependent variable & $\begin{array}{l}\text { Independent } \\
\text { variables }\end{array}$ & Std. coef. & $\mathbf{R}^{\mathbf{2}}$ \\
\hline QUICKI & $\mathrm{BMl}$ & $-0.413(0.0253)$ & $0.512(0.0004)$ \\
(Model 1) & $\mathrm{M}_{0}$ & $-0.413(0.0253)$ & \\
QUICKI & Log $_{\mathrm{e}}$-leptin & $-0.414(0.0193)$ & $0.522(0.0003)$ \\
(Model 2) & $\mathrm{M}_{0}$ & $-0.438(0.0140)$ & \\
Log $_{\mathrm{e}}$-MI & $\mathrm{BMl}$ & $-0.400(0.0298)$ & $0.512(0.0004)$ \\
(Model 3) & $\mathrm{M}_{0}$ & $-0.426(0.0215)$ & \\
Log $_{\mathrm{e}}$-MI & Log $_{\mathrm{e}}$-leptin & $-0.394(0.0258)$ & $0.517(0.0003)$ \\
(Model 4) & $\mathrm{M}_{0}$ & $-0.453(0.0118)$ & \\
\hline
\end{tabular}

$\mathrm{M}_{0}$ and $\mathrm{G}_{0}$ are fasting plasma mannose and glucose levels, respectively Probabilities are indicated in parentheses

MI Matsuda index

association could not be evaluated. Third, this study may have been affected due to selection bias and not be representative of the broader population, since data were collected at a single institute in Japan. Further multicenter collaborative research is needed.

\section{Conclusion}

This study established that fasting plasma mannose was correlated with insulin sensitivity independent of BMI in Japanese individuals with diabetes.

\section{Abbreviations \\ OGTT: oral glucose tolerance test; IRI: immunoreactive insulin; ELISA: enzyme- linked immunosorbent assay; HbA1c: glycated hemoglobin; WHO: World Health Organization; NGT: normal glucose tolerance; IGM: impaired glucose metabolism; IFG: impaired fasting glucose; G: glucose; I: IRI; IGI: insulinogenic index; HOMA: homeostasis model assessment; QUICKI: quantitative insulin sensitivity check index; $\mathrm{Dl}_{0}$ : oral disposition index; $\mathrm{HDL}$-C: high-density lipoprotein-cholesterol; ANOVA: analysis of variance; BMI: body mass index. \\ Authors' contributions \\ EA, YT and S Fujimoto participated in the design of study. EA, S Funakoshi, KY, $\mathrm{SH}, \mathrm{SO}$, and HT participated in data collection. EA and S Fujimoto participated in analysis of data and wrote the manuscript. All authors read and approved the final manuscript.}

\section{Acknowledgements}

The authors thank Ms. Reiko Matsumoto from Department of Endocrinology, Metabolism, and Nephrology, Kochi Medical School, Kochi University for technical assistance.

\section{Competing interests}

The authors declare that they have no competing interests.

\section{Availability of data and materials}

The ethics committee imposed restrictions to data access and sharing. Individuals who wish to access our data must obtain further permission from the committee, which can be achieved by contacting the corresponding author. 


\section{Consent for publication \\ Not applicable.}

\section{Ethics approval and consent to participate}

The study protocol was approved by the Ethical Review Board of Kochi Medical School. Informed consent was obtained from each patient.

\section{Funding}

The authors have received no funding support regarding this study.

\section{Publisher's Note}

Springer Nature remains neutral with regard to jurisdictional claims in published maps and institutional affiliations.

Received: 24 August 2018 Accepted: 29 November 2018

Published online: 04 December 2018

\section{References}

1. Hawkins M, Rossetti L. Insulin resistance and its role in the pathogenesis of type 2 diabetes. In: Kahn CR, Weir GC, King GL, Jacobson AM, Moses AC, Smith RJ, editors. Joslin's diabetes mellitus. 14th ed. Philadelphia: Lippincott Williams \& Wilkins; 2005. p. 425-7.

2. Newgard CB, An J, Bain JR, Muehlbauer MJ, Stevens RD, Lien LF, et al. A branched-chain amino acid-related metabolic signature that differentiates obese and lean humans and contributes to insulin resistance. Cell Metab. 2009;9:311-26.

3. Gall WE, Beebe K, Lawton KA, Adam KP, Mitchell MW, Nakhle PJ, RISC Study Group, et al. a-Hydroxybutyrate is an early biomarker of insulin resistance and glucose intolerance in a nondiabetic population. PLoS ONE. 2010;5:e10883.

4. Lee S, Zhang C, Kilicarslan M, Piening BD, Bjornson E, Hallström BM, et al. Integrated network analysis reveals an association between plasma mannose levels and insulin resistance. Cell Metab. 2016;24:172-84.

5. Alton G, Hasilik M, Niehues R, Panneerselvam K, Etchison JR, Fana F, et al. Direct utilization of mannose for mammalian glycoprotein biosynthesis. Glycobiology. 1998;8:285-95.
6. Sone $H$, Shimano H, Ebinuma H, Takahashi A, Yano Y, lida KT, et al. Physiological changes in circulating mannose levels in normal, glucose-intolerant, and diabetic subjects. Metabolism. 2003;52:1019-27.

7. Yoshimura K, Hirano S, Takata H, Funakoshi S, Ohmi S, Amano E, et al. Plasma mannose level, a putative indicator of glycogenolysis, and glucose tolerance in Japanese individuals. J Diabetes Investig. 2017;8:489-95.

8. World Health Organization. Definition and diagnosis of diabetes mellitus and intermediate hyperglycemia: report of a WHO/IDF consultation. Geneva: World Health Organization; 2006.

9. Considine RV, Sinha MK, Heiman ML, Kriauciunas A, Stephens TW, Nyce $M R$, et al. Serum immunoreactive- leptin concentrations in normalweight and obese humans. N Engl J Med. 1996;334:292-5.

10. Ohmi S, Ono M, Takata H, Hirano S, Funakoshi S, Nishi Y, et al. Analysis of factors influencing glucose tolerance in Japanese patients with nonalcoholic fatty liver disease. Diabetol Metab Syndr. 2017;9:65.

11. Peddinti G, Cobb J, Yengo L, Froguel P, Kravić J, Balkau B, et al. Early metabolic markers identify potential targets for the prevention of type 2 diabetes. Diabetologia. 2017;60:1740-50.

12. Mardinoglu A, Stančáková A, Lotta LA, Kuusisto J, Boren J, Blüher M, et al. Plasma mannose levels are associated with incident type 2 diabetes and cardiovascular disease. Cell Metab. 2017;26:281-3.

13. Akazawa S, Metzger BE, Freinkel N. Relationships between glucose and mannose during late gestation in normal pregnancy and pregnancy complicated by diabetes mellitus: concurrent concentrations in maternal plasma and amniotic fluid. J Clin Endocrinol Metab. 1986;62:984-9.

14. Pitkänen E. Mannose, mannitol, fructose and 1,5-anhydroglucitol concentrations measured by gas chromatography/mass spectrometry in blood plasma of diabetic patients. Clin Chim Acta. 1996;251:91-103.

15. Pitkänen OM, Vanhanen H, Pitkänen E. Metabolic syndrome is associated with changes in D-mannose metabolism. Scand J Clin Lab Invest. 1999;59:607-12.

16. Taguchi T, Yamashita E, Mizutani T, Nakajima H, Yabuuchi M, Asano N, et al. Hepatic glycogen breakdown is implicated in the maintenance of plasma mannose concentration. Am J Physiol Endocrinol Metab. 2005:288:E534-40.
Ready to submit your research? Choose BMC and benefit from:

- fast, convenient online submission

- thorough peer review by experienced researchers in your field

- rapid publication on acceptance

- support for research data, including large and complex data types

- gold Open Access which fosters wider collaboration and increased citations

- maximum visibility for your research: over $100 \mathrm{M}$ website views per year

At $\mathrm{BMC}$, research is always in progress.

Learn more biomedcentral.com/submissions 